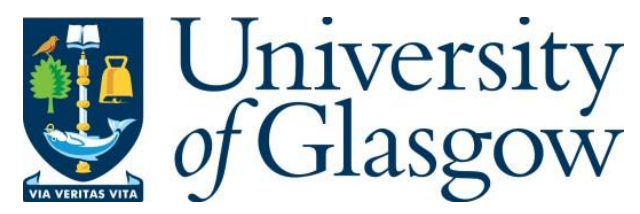

Skipper, Y. and Douglas, K. M. (2016) The impact of a selective entry examination on children's feelings as they approach the transition to secondary school. British Educational Research Journal, 42(6), pp. 945-961.

There may be differences between this version and the published version. You are advised to consult the publisher's version if you wish to cite from it.

This is the peer reviewed version of the following article Skipper, Y. and Douglas, K. M. (2016) The impact of a selective entry examination on children's feelings as they approach the transition to secondary school. British Educational Research Journal, 42(6), pp. 945-961, which has been published in final form at http://dx.doi.org/10.1002/berj.3242. This article may be used for non-commercial purposes in accordance with Wiley Terms and Conditions for Self-Archiving.

http://eprints.gla.ac.uk/185732/

Deposited on: 2 May 2019

Enlighten - Research publications by members of the University of Glasgow http://eprints.gla.ac.uk 
The Impact of a Selective Entry Examination on Children's Feelings as they Approach the Transition to Secondary School

Yvonne Skipper and Karen M. Douglas

${ }^{1}$ Keele University

${ }^{2}$ University of Kent

Word count (exc. figures/tables/references): 6345

*Requests for reprints should be addressed to Dr Yvonne Skipper, School of Psychology, Dorothy Hodgkin Building, Keele University, Keele, Staffordshire, ST5 5BG, United Kingdom email: y.skipper@keele.ac.uk 


\begin{abstract}
In the current study we examined how different experiences of a secondary school selective entry examination influenced children's feelings about themselves, school, and intelligence as they approached transition. Children were recruited from three English schools that use a selective entry examination to stream students into secondary schools based on ability (98 children aged around 10) and were assessed at two time points. At Time 1 children had recently decided whether to take the exam, and at Time 2 children had received their exam results. At each time children completed measures of theory of intelligence, locus of control, self-esteem, and feelings about the school system. At Time 1, children who intended to take the exam showed more positive outcomes than those who did not. However, they were also more likely to hold a fixed view of intelligence, which has been associated with longer-term negative outcomes. Similarly at Time 2 children who had passed the exam showed more positive outcomes than those who had failed or had not taken the exam, but again they were more likely to hold a potentially maladaptive fixed view of intelligence. Those who failed the exam were indistinguishable from those who had not taken the exam. These results suggest that passing the selective exam can lead to positive outcomes for children, except in terms of their view of intelligence. However, failing and not being given the opportunity to sit the exam leads to consistently negative outcomes. The potential implications of these results are discussed.
\end{abstract}

Keywords: transition to secondary school, selective exam, theory of intelligence 
The Education Act (1944) created a selective examination for children entering secondary school in England and Wales (the so called "Eleven Plus") as a way of separating the top performing students who would transition into "grammar schools" (typically around $25 \%$ ) from other pupils who would transition to "secondary modern" or "secondary technical" schools. In 2012-2014, 96\% of grammar school children achieved passing grades for at least five subjects at age 16 including English and Maths, compared to 55\% in other schools (Grammar School Statistics, 2015). Although these differences could be caused by the selection of higher achieving children, Atkinson, Gregg and McConnell (2006) found that children who attend grammar schools in areas which have a selective education system outperform similar children in non-selective education systems. Additionally children who do not attend grammar schools in a selective system tend to underperform when compared to similar children in a non-selective system. Therefore, children who attend grammar schools are likely to leave school with better examination results and arguably have better career prospects than those who do not.

Major concerns about segregation and class inequality led to the abolishment of the grammar school system in most of England and Wales as part of the Education Act of 1976 (Jackson \& Marsden, 1962; Douglas, 1964). At this time, most grammar schools closed or were amalgamated with "comprehensive schools" (the replacement of secondary modern and technical schools). However, some British counties such as Kent in the south east of England maintained the selective system. There are currently 163 grammar schools remaining with a total of 164,000 pupils (Grammar School Statistics, 2015) of which nearly 30\% are in Kent (National Grammar Schools Association, 2015). Ten Local Education Authorities have a fully selective system and a further 26 have one or more grammar schools in their area (Grammar School Statistics, 2015). The potential impacts of selective entry exams are 
therefore still of concern. In this paper, we focus on how children in such educational systems feel about their transition to secondary school.

Transition to secondary school represents an important life event for children. They experience a significant amount of change in a short space of time, such as a range of new teachers, different subjects, and new peer groups (Sirsch, 2003). It is therefore unsurprising that approaching the transfer from primary to secondary school can be stressful for children (West, Sweeting \& Young, 2010; Tobbell, 2003). Indeed, the transfer has been found to lead to negative academic outcomes in some children such as a drop in academic performance (McGee, Ward, Gibbons, \& Harlow, 2003; Gutman \& Midgley, 2000), a drop in school grades (Otis, Grouzet, \& Pelletier, 2005) and reduced academic motivation (Eccles \& Midgley 1989; Wigfield, Eccles, MacIver, Reuman, \& Midgley, 1991). A large proportion of secondary school pupils make no gain in their levels in English (49\%) and Maths (33\%) by the end of their first year (Galton, Morrison, \& Pell, 2003). However, school transition is not always a negative event. Whilst some children perceive the move as a threat, others perceive it positively, as a challenge or opportunity to grow and learn (Sirsch, 2003). The responses that children develop upon entering secondary school can set the pattern for how they will continue to respond throughout their years, thus shaping their attitudes to learning and future choices (Reyes, Gillock, Kobus \& Sanchez, 2000; Smyth, McCoy \& Darmody, 2004). The importance of a successful transition process cannot, therefore, be overstated.

The majority of the research on children's transition to secondary education has focused on the impact of transition, following students through transition and examining changes over time, or asking children to reflect back upon their transition experiences. Some research has examined students' feelings about the upcoming transition (Akos, 2002; Brown \& Armstrong, 1982; Cotterell, 1982; Jennings \& Hargreaves, 1981; Mitman \& Packer, 1982; Murdoch, 1986). However, this research often examined feelings before transition in order to 
create a baseline for examining changes following transition. Additionally, this research has usually been conducted in schools that use geographical streaming so that the experiences of all children are broadly similar. We argue that the presence of a selective entry examination may have a strong impact on children's feelings about the upcoming transition. Such examinations create a disparity between children before they move to secondary school, which may exert a significant influence on their feelings about themselves and school even before transition has begun. Children who feel positive about themselves, for example in terms of self-esteem and locus of control, and feel positive about the school system, are likely to experience more positive outcomes during transition. However, how selective examinations influence these processes has, to our knowledge, not yet been examined.

A further factor concerning selective entry examinations is that not all children take them. In most areas, and in the area where the research was conducted, teachers and parents decide which children should be put forward to sit the exam based on current performance and likelihood of success. Therefore, some children will not take the exam at all, some will pass, and others will fail. This creates another unusual situation for children who would ordinarily be accustomed to taking the same exams at the same time as all other pupils. The current study aims to explore how different experiences of the selective entry exam influence children's feelings about themselves and the school system in the time leading up to transition. We focus specifically on children's theory of intelligence, locus of control, selfesteem, and feelings about the student-teacher relationship.

\section{Theory of intelligence}

Theory of intelligence has been found to have a powerful impact on school achievement particularly across educational transitions. Dweck (1999) suggests that people can view intelligence in entity or incremental forms. Entity theorists believe that intelligence is a trait - people have a certain amount of intelligence and it cannot be changed. In contrast, 
incremental theorists believe that that intelligence is something that can be cultivated through learning. Incremental theorists believe that intelligence can be changed with effort. Therefore they are more likely to hold learning goals, which are goals focussed on challenging oneself and developing new knowledge and skills. Similarly, incremental theorists view failure as an indicator that further work is needed. They are therefore likely to persist in their efforts and often improve following failure. In contrast, entity theorists who believe intelligence is fixed are concerned about proving their abilities and therefore often hold performance goals where they aim to get a high mark. They view failure as an indication that they do not have the talent to succeed, and they therefore disengage from the task, showing low persistence and self-handicapping behaviours.

Therefore, an incremental theory of intelligence is associated with positive behaviours, which are associated with higher academic achievement (Dweck, 1999; Dweck, Chiu \& Hong, 1995 Aronson, Fried, \& Good, 2002; Blackwell, Trzesniewski, \& Dweck, 2007; Hong, Chiu, Dweck, Lin, \& Wan, 1999; Heyman \& Dweck, 1998). An incremental theory of intelligence may be particularly important for success during transition due to the fact that children are studying new topics. Specifically, holding learning goals may focus children on improving their knowledge rather than aiming for high marks initially. Furthermore, the expected standard of work in secondary school increases in all subjects, therefore increasing the likelihood of failure (Seidman, Allen, Aber, Mitchell, \& Feinman, 1994). Therefore, children are more likely to succeed in secondary school if they hold an incremental theory (Blackwell et al., 2007).

Selective entry exams were originally developed to tap 'natural ability' and it was asserted that performance on tests such as these could not be improved by tutoring, thus giving all children an equal opportunity to obtain high marks and gain a place in a good secondary school regardless of background (Vernon, 1957). However, using a selective 
exam to stream children into different secondary schools promotes an extreme entity view of intelligence. In effect, children are being given the message that their performance in a primary school exam can be used to predict whether they are likely to perform well into their later years of education. This also sends a message to children that some of them are simply cleverer than others regardless of the effort they could put in to prepare for the test. Selective entry examinations are therefore likely to encourage an entity theory of intelligence, especially in children who take them.

\section{Feelings about the self}

\section{Locus of control}

Locus of control is the extent to which people feel that they can control events that affect them. It exists on a continuum ranging from internal, where outcomes are seen as within personal control, to external, where outcomes are perceived to be outside personal control (Rotter, 1975). A more internal locus of control has been associated with a number of positive educational outcomes such as a high grade point average (Shepherd, Fitch, Owen \& Marshall, 2006) and resilience during transition (Newman \& Blackburn, 2002). It is argued that an internal locus of control leads people to take positive action to achieve their goals (Rotter, 1990; Lefcourt, 1976; Oswald, Walker, Krajewski, \& Reilly, 1994). They feel that their efforts can lead to positive change.

Locus of control is relatively stable but can be changed via behavioural reinforcement (Reimanis, 1974) acculturation (Marks, 1998) and through development (Gatz \& Carel, 1993). The decision as to whether children should take the selective entry exam rests primarily with the teacher or parents who may decide not to put children forward if they are unlikely to pass. This is likely to influence children's locus of control since somebody else decides whether they will be given the option to sit the exam or not. Failure may also have a negative impact on locus of control. Those with an internal locus of control have been found 
to attribute failure to variables which they can control (e.g. effort and technique). Those with an external locus of control on the other hand often attribute failure to variables outside their control (e.g. luck; Rotter, 1966). However, it may also be that failure leads children to show a more external locus of control (Cunningham, Gerard \& Miller, 1978). Therefore, passing the exam is likely to encourage a more internal locus of control compared to failing. Further, children who do not take the test are likely to have a more external locus of control compared to those who do.

\section{Self-esteem}

Self-esteem is defined as feeling competent to deal with challenges in life and being worthy of happiness (Branden, 1969). High self-esteem is linked to higher resilience in children (Gilligan, 2000). Children who have low self-esteem do not feel that they have the tools to cope with threats and challenges; they are consequently more vulnerable to negative responses to difficulties (Baumeister 1993). Low self-esteem has been identified as a risk factor during transitions (Newman \& Blackburn, 2002). However, those with a healthy selfesteem may cope with the rigors of transition, and benefit in terms of academic and personal growth (Freudenthaler, Spinath \& Neubauer, 2008).

It has long been theorised that the experience of failure will lead to negative outcomes such as increased feelings of helplessness (Mikulincer, 1994; Seligman, 1975) and a reduction in self-esteem (McFarland \& Ross, 1982). Research suggests that students show lower self-esteem on days in which they received lower grades than they would have liked (Crocker, Karpinski, Quinn, \& Chase, 2003) and that this is particularly prevalent when their self-worth is contingent on their academic performance (Crocker \& Wolfe, 2001).

Children are often advised not to take the selective entry exam if their teachers or parents feel that they are likely to fail. It is therefore likely that being asked to take the exam will be 
associated with higher levels of self-esteem, but that failing the exam will be associated with lower levels of self-esteem.

\section{Feelings about school}

Thus far, discussion has mainly focused on feelings about the self. However, perceptions of the school system are also important during transition. Maintaining positive feelings about school is vital as it is strongly linked to engagement with secondary school and thus completion of school and long-term achievement (Skinner, Welborn \& Connell, 1990). Those who do not maintain some positive feelings towards school and their teachers risk becoming disengaged, and this can have a negative effect on their performance and future choices (Wassell, Preston \& Jones, 2007). Studies that have followed children across the transition from primary to secondary school have found that student-teacher relationships are rated as increasingly negative during this time and children who rate their relationships with teachers more negatively experience even greater disruption (Newman, Myers, Newman, Lohman \& Smith, 2000). Furthermore, there tends to be a decline in children's liking for their school (Barber \& Olsen, 2004) as well as their attachment to school and feelings of belonging (Newman, Newman, Griffen, O'Connor, \& Spas, 2007).

Therefore it is important to understand what features of transition can lead to more negative perceptions of student-teacher and student-school relationships. It is likely that a selective entry examination may influence children's feelings about school before the transition even occurs, due to differential experiences of children in the same class. In particular, pupils who are asked to take the exam may feel encouraged and supported, and therefore experience positive feelings about the school and their teachers, compared to those who are not encouraged to take the exam. Passing the exam may also have positive impact on pupils' feelings about their school, compared to failure.

\section{The current research}


The current study examined the impact of a selective secondary school exam on the experiences of children in the period leading up to transition. Children completed questionnaires measuring their perceptions of intelligence, feelings about the self (locus of control and self-esteem) and feelings about school at two different time points. Time 1 was when children had recently decided whether or not to take the exam and Time 2 was when children had recently received their results. It was hypothesised that:

1. Theory of intelligence: At Time 1, pupils who were taking the exam would be more likely to hold an entity theory of intelligence, and less likely to hold an incremental theory of intelligence, than those who were not taking the exam. At Time 2, pupils who had passed the exam would be more likely to hold an entity theory of intelligence, and less likely to hold an incremental theory of intelligence, than those who did not pass.

2. Locus of control: At Time 1, pupils who were taking the exam would show higher internal locus of control than pupils who were not taking the exam. At Time 2, pupils who had passed the exam would show higher internal locus of control than pupils who did not pass.

3. Self-esteem: At Time 1, pupils who were taking the exam would show higher levels of self-esteem than those who were not taking the exam. At Time 2, pupils who had passed the exam would show higher levels of selfesteem than those who did not pass.

4. Feelings towards school: At Time 1, pupils who were taking the exam would feel more positively about the school and teachers than those who were not taking the exam. At Time 2, pupils who had passed the exam would feel more positively about the school and teachers than those who did not pass. 


\section{Method}

\section{Participants and design}

Letters were sent to seven schools in Kent that utilised selective testing (where the selective exam is called the "Kent Test"). These schools were chosen because they were coeducational and we also chose to approach schools from a range of towns across Kent. Perhaps due to the strong feelings that the Kent Test often evokes, only three of the schools elected to participate in the study. Across the three schools, there were 98 participants (54 boys and 43 girls). The majority of participants were White British (N=92) and all spoke English as their primary language. At Time 1 the mean age of participants was 9 years 11 months.

\section{Materials}

All children completed preliminary measures of age, gender and ethnicity. At Time 1, children were asked "Will you take the Kent Test?" and at Time 2 they were asked "Did you pass the Kent Test?" Children answered these questions by circling either "Yes" or "No". At each time, children also completed measures about their feelings concerning intelligence, the self (locus of control and self-esteem) and the school system (i.e. their school and teachers).

\section{Theory of intelligence}

Theory of intelligence was measured using Dweck's (1999) theory of intelligence scale, comprising six statements. Three advocated an entity theory (e.g., "You can learn new things but you can't really change your basic intelligence") and three advocated an incremental theory (e.g., "No matter how much intelligence you have you can always change it quite a bit"). Children were asked how much they agreed with each statement on a scale of 1 "strongly disagree" to 6 "strongly agree" $\left(\alpha_{\text {entity }}=.76 ; \alpha_{\text {incremental }}=76\right)$.

\section{Feelings about the self}

Locus of control 
The Nowicki-Strickland Locus of Control Scale (Nowicki \& Strickland, 1971) shortened measure for children aged 6-12 indicates whether children feel that they control their lives or whether most of the things that happen to them are caused by other people or luck. It consists of 20 questions that are themed around control, such as "Are some kids just born lucky?" to which children responded "yes" or "no" $(\alpha=.63)$.

\section{Self-esteem}

Self-esteem was measured using the Piers Harris Children's Self-Concept Scale, Second Edition (Piers-Harris 2, 2002). The complete scale consists of 60 items measuring different kinds of self-esteem but was deemed too long for the purposes of this study and was therefore shortened. We removed measures related to popularity and physical appearance which were less relevant to this study and used only measures relating to freedom from anxiety, intellectual and school status, behavioural adjustment, happiness and satisfaction to produce a 26 item scale including statements such as "I am good in my schoolwork" to which children responded "yes" or "no" $(\alpha=.84)$.

\section{Feelings about school}

It was felt that many children would be unclear as to what the "school system" meant, so questions were phrased in terms of their teacher and school. Children were therefore asked: "How much do your teachers and school care about you?", "How much do your teachers and school care about your future?" and "How much do you like your teachers and school?". These questions were measured on a six-point scale ranging from "not at all" to "very much". These items were combined to create a single variable of "feelings about the school system" $(\alpha=.79)$.

\section{Procedure}

Informed consent was obtained from head teachers, parents and finally verbal consent was obtained from the children. At both Time 1 and Time 2, children were given the paper 
questionnaires during class time and worked through them individually. Once they had completed the entire study children were verbally debriefed, given a small gift and also given a written debrief to take home to their parents.

\section{Results}

Means and standard deviations are presented in Tables 1 (Time 1) and 2 (Time 2). In all analyses, a significance level of .05 was used.

\section{Theory of intelligence}

At Time 1, 60 children intended to take the exam while 38 did not. An independent samples t-test indicated that children who intended to take the exam showed more of an entity theory of intelligence $t(93)=2.53, p=.013$, and less of an incremental theory of intelligence $t(92)=-2.79, p=.006$, than those who did not intend to take the exam.

At Time 2, nineteen students passed, 41 failed and 38 did not sit the exam. One way ANOVAs indicated that those who passed the exam showed more of an entity theory of intelligence $F(2,97)=3.25, p=.043, \eta^{2}=.07$ and slightly less of an incremental theory of intelligence $F(2,97)=3.01, p=.054, \eta^{2}=.07$ than those who had not passed the exam, or who had not taken the exam. Planned contrasts comparing those who passed with both those who failed and those who did not take the exam (combined) showed that pupils who passed had higher levels of entity theory of intelligence $t(95)=-2.45, p=.016$, and lower levels of incremental theory of intelligence $t(95)=2.44, p=.017$. Additionally, there were no significant differences between those who failed and those who did not take the exam: entity theory of intelligence $t(77)=-.732, p=.720$, incremental theory of intelligence $t(77)=-.299$, $p=.154$. This supports Hypothesis 1 .

\section{Locus of control}

At Time 1, an independent samples t-test revealed that children who intended to take the exam showed higher levels of internal locus of control, $t(88)=2.60, p=.011$ than those 
who were not taking the exam. At Time 2, a one way ANOVA indicated that children who passed the exam showed a more internal locus of control $F(2,92)=3.72, p=.028, \eta^{2}=.11$ than those who did not pass the exam. Planned contrasts comparing those who passed with both those who failed and those who did not take the exam (combined) showed that pupils who passed showed a higher internal locus of control $t(90)=-2.72, p=.008$. Again there were no differences between those who failed and did not take the exam $t(73)=.076, p=$ .606. This supports Hypothesis 2.

\section{Self-esteem}

At Time 1, an independent samples t-test revealed that children who intended to take the exam showed higher self-esteem, $t(82)=2.99, p=.004$, than those who were not taking the exam. At Time 2, a one way ANOVA indicated that children who passed the exam showed higher self-esteem, $F(2,88)=5.47, p=.006, \eta^{2}=.16$ than those who did not pass the exam. Planned contrasts comparing those who passed with both those who failed and those who did not take the exam (combined) showed that pupils who passed showed higher selfesteem $t(86)=-2.98, p=.004$. However, there were no differences between those who failed and those who did not take the exam $t(69)=1.195, p=.244$. This supports Hypotheses 3 .

\section{Feelings about school}

At Time 1, an independent samples t-test revealed that children who intended to take the exam felt more positive about the school system than those who were not taking the exam, $t(94)=2.74, p=.007$. This supports Hypothesis 4 .

However, contrary to Hypothesis 4, at Time 2 a one way ANOVA illustrated that there was no difference between children who passed, failed and did not pass in terms of perceptions of the school system $F(2,97)=.98, p=.378$.

\section{Changes over time}


Changes from Time 1 to Time 2 were not significant for any variables, according to paired samples t-tests. Additionally, experiences within the exam system (passing, failing or not taking the exam) did not influence changes over time, according to a repeated measures ANOVA.

Overall, these findings suggest that failing and not taking the exam led to similarly negative outcomes in terms of feelings about the self. However, both were equally likely to be associated with an adaptive incremental theory of intelligence.

\section{Discussion}

As predicted, the intention to take the selective exam was associated more with an entity theory and less with an incremental theory of intelligence. Additionally, children who passed the exam showed more of an entity theory and less of an incremental theory of intelligence than those who failed or did not take the exam. Those who intended to take the exam showed a more internal locus of control, and those who passed also showed a more internal locus of control. Children who intended to take the exam showed higher self-esteem. Similarly, those who passed showed higher self-esteem. Children who intended to take the exam felt more positive about the school system. Thus far, all findings supported our hypotheses. However, contrary to Hypothesis 4 there were no differences between those who had passed the exam and those who had failed or not taken the exam in terms of their feelings about school. Importantly, there were no significant differences between those who failed the exam and those who did not take the exam, which suggests that both have a similarly negative impact on children's feelings about the self and about school.

Approaching transfer to secondary school is often stressful for children (West et al., 2010; Tobbell, 2003) and transition can lead to negative outcomes such as a drop in performance (Galton et al., 2003) and reduced academic motivation (Wigfield et al., 1991). However, the period before the transition is also vital, and the current findings suggest that 
children's feelings about themselves and the school system begin to change even before they undergo transition. Feeling positive about the self is important during this transition as children with high self-esteem are more likely to show resilience in the face of change (Gilligan, 2000), and those who have an internal locus of control are also likely to take positive action to help make their transition a more positive experience (Rotter, 1990).

The current results suggest that not taking the exam may be associated with negative feelings about the self. Children who did not take the exam showed lower self-esteem and in addition, they showed a more external locus of control. Within this group, it is impossible to know which pupils made the choice not to take the exam and which were told not to take it, but regardless of this, the negative effects of not taking the exam are evident. Furthermore, pupils who failed and who did not take the exam showed similarly negative feelings about the self, and both felt considerably more negative than those who passed the exam. There may be significant negative consequences for these children concerning how they experience the transition to secondary school (Gilligan, 2000; Rotter, 1990), potentially making a challenging time even more difficult for these children. Many previous studies have examined how educational professionals can promote an easier transition to secondary school, such as by identifying children who are more at risk of a poor transfer experience (Galton, Gray \& Ruddock, 1999) and evaluating interventions to ease the transition (Evangelou, Taggart, Sylva, Melhuish, Sammons \& Siraj-Blatchford, 2008). However, this research suggests that a transfer system that involves a selective entry test may already have a negative impact on all the children who fail or do not take the exam.

Additionally, previous research suggests that children who feel positive about the school system are more likely to maintain engagement in the system and are therefore more likely to perform well in secondary school (Newman et al, 2007). The current research suggests that the selective entry exam led children who did not take the exam to feel more 
negative about the school system, than those who did take the exam. This is understandable perhaps because they were being left "behind" other pupils who did take the exam. However, once children had taken the exam they felt equally positive about the school system regardless of their own experience. Perhaps time reduced any negative feelings that may have been present in those who did not take the exam. Although this is not supported by significant changes in any of the three groups, there was a regression towards the mean, which could indicate why this difference was not significant at Time 2.

However, although children who passed the exam showed positive outcomes in terms of feelings about the self, they were also more likely to hold an entity theory of intelligence and less likely to hold an incremental theory. This, as previously discussed, may have a lasting negative impact on children's performance in secondary school, being associated with performance goals and a negative response to failure (Dweck, 1999; Dweck, et al., 1995), which is particularly problematic during transition.

Therefore, not taking, or failing the selective exam was associated with children feeling more negative about themselves which may lead them to feel more negative about the upcoming transition to secondary school and also less able to cope with the transition when they leave primary school. Abolishing the use of the selective entrance exam and instead using regular measures of student progress may be a better way to decide who will attend grammar schools. This would mean that the differences between children's results would be less visible within the class, as there are simply 'levels' and not a cut-off mark for passing or failing. This may therefore perhaps negate the detrimental effect of not taking the exam or failing.

Additionally, taking the exam was associated with a higher entity view of intelligence, which may make it more difficult to succeed in secondary school. Those who failed or did not sit the exam were more likely to hold an incremental theory and thus may cope better 
with the academic challenges of secondary school. Streaming children based on regular progress scores may also negate this effect. If all children are tested in the same way, they may be more likely to view the tests as examining effort and technique rather than innate ability. Giving everyone the chance to take the tests means that everyone could perform well, thus promoting a more incremental view of intelligence.

The first selective secondary school entry test, known as the Eleven Plus, was originally developed to tap natural ability and to therefore give all students the opportunity to attend the best secondary schools, rather than those who could afford extra tutoring (Vernon, 1957). However, it is clear that a number of children do receive tutoring for current selective entry exams (Bunting \& Mooney, 2001). Those children who receive tutoring also tend to perform better in the exam (Bunting \& Mooney, 2001; Egan \& Bunting, 1991). Furthermore, many of the parents who do pay for external tutoring for their children are employed in nonmanual occupations (West, Noden \& Edge, 1998) suggesting that upper and middle class children are more likely to be able to afford extra tutoring which can help their children to pass the exam and secure positions in the higher performing grammar schools. Supporting this idea, the percentage of children receiving free school meals in grammar schools is not representative of their local areas and in 2007, was as low as one-fifth of their local area (Department for Children Schools and Families, 2008). This is not to say that the geographical streaming system does not suffer from similar problems. Indeed, research suggests that many middle class parents move home to live in the catchment areas for better performing schools and areas with better schools are found to have markedly higher house prices (Gibbons \& Machin, 2008; Black \& Machin 2010). Therefore, the impact of privilege in education is still clear regardless of the type of streaming system. Thus, perhaps basing the streaming on regular progress scores, giving all students the opportunity to sit the exams and devoting extra class time to coaching could help children have a more equal opportunity of 
passing. This may also help to minimise the 'entity' view of intelligence since it would be clear that all children could perform well with effort, good techniques and extra coaching.

A limitation of the current research was that it only examined children's feelings before they made the transfer to secondary school. It is important to follow children into secondary school and examine how they actually experience the transfer. Much research on transition is not longitudinal and either focuses on children looking forward or looking back on transition, which can be problematic as it is difficult to predict how one will feel or to recall exactly how one has felt at a particular time (West, Sweeting \& Young, 2010). Therefore, future research could examine whether those who passed the exam maintained their positive feelings about themselves across the transition and whether this led to an easier transfer experience.

Furthermore, in this study we worked with children when they had recently decided whether they would take the exam or not. There were significant differences on the dependent measures between those who intended to take the exam and those who did not intend to take the exam even at Time 1. It could therefore be argued that the results of this study are a consequence of children's different levels of attainment rather than a result of their experience with the Kent Test. This is perhaps unlikely since previous research suggests that it is pupils who hold an incremental theory of intelligence who show higher performance levels (Blackwell, Trzesniewski, \& Dweck, 2007). Nevertheless, attainment is an important factor to consider in future research. It would therefore be useful to begin working with children earlier in the academic year to examine how knowledge of the exam and early discussions influence feelings about the exam, school and the self. Working with children across a longer time period would give a more complete picture of the long-term impact of the selective entrance exam from early discussions to examining how children cope with the transition and perform in secondary school. 
This longer term analysis would also allow researchers to examine changes over time. The current study did not find changes over time in any of the variables examined, perhaps due to the fact that we only tested children once they had decided whether to take the exam, or perhaps due to a relatively small sample size in each group, which is another limitation of this research. Therefore, future research could examine changes over a longer time period with a larger sample.

In addition, future research could examine children's feelings about the selective testing by using alternative methodologies. In particular, interviews and focus groups may be used to allow a deeper exploration of the complex feelings experienced by the young children who are confronted with the test. Whilst the survey method allows researchers to work with larger groups and generalise across settings, interviews and focus groups would generate richer data to explore more multifaceted questions about the impact of selective testing on children.

Results from this research have implications beyond the Kent Test and similar selective secondary school entry exams. Children are sometimes encouraged not to take exams that teachers do not think they are likely to pass as they feel that failure would be a negative experience (Thompson, Davidson, \& Barber, 1995; Dweck 1999). However, our results suggest that not taking the exam leads to equally negative outcomes as actually failing. It would therefore be valuable to further examine the impact of being advised to take lower levels of papers. Previously, secondary school exams taken in the fourth year of secondary school in Britain (GCSEs) involved a tiered system where students would take higher or lower level papers based on their expected grades. This led to difficult decisions as to which tier of paper students should complete if they were on the borderline. For example, a student who is predicted to achieve a grade $\mathrm{C}$ or $\mathrm{D}$ may be encouraged to try for the higher tier, but if they failed to pass this paper then they would not receive a GCSE in the subject. 
In contrast, if they took the lower tier paper, even if they achieved full marks they could not achieve a high grade. This has led to a move towards non-tiered papers and as of 2015 certain GCSE subjects, offered by some exam boards, will be non-tiered, such as English language and literature (OCR, 2015). However, Maths and some other subjects will remain tiered in order to stretch the most able students and allow the less able students to demonstrate their skills. Tiered papers are thought to lead to students working towards achievable goals. However, being told not to sit higher papers may lower students' expectations of themselves, and those of their teachers, which may in turn set them on a path to low achievement (Farkas, Grobe, Sheehan \& Shaun, 1990; Rosenthal \& Jacobson, 1966). Tiering also requires teachers to make overt their expectations of student performance and this expectation is then released to the student, which also raises issues for the consequential validity of the exams (Elwood \& Murphy, 2002). Tiered systems may also have differential consequences for different sub groups of children (Stobart, White, Elwood, Hayden \& Mason, 1992). For example, teachers are more likely to encourage boys to take higher tiers of maths papers than girls and children from ethnic minority groups are also more often entered into lower tiers (Gillborn \& Youdell, 2000). These effects are particularly strong in maths, which is the subject in which tiers are remaining (Elwood \& Murphy 2002). This suggests that tiered papers can lead to a lack of parity between students. Our results echo this, in that children who did not take the selective exam and those who failed felt equally negative. This again suggests that perhaps all children should be able to sit non-tiered exams in order to lead to equality and higher aspirations for all. However, further research is needed in order to examine the impact of tiered exams, not only on performance, but on students' feelings about themselves and aspiration levels for the future.

In summary, the results of this study suggest that children's feelings about intelligence, themselves, and school can be very different depending on their experience of a 
selective entrance exam for secondary school. A greater understanding is needed of how transition systems influence children's feelings and ability to cope with the transition. This will allow researchers to understand what factors are associated with negative outcomes and in turn what can be done at an institutional level to minimise negative experiences and maximise positive experiences for all children. Furthermore, these results suggest that not taking a selective exam may have similarly negative consequences to failing, which has implications not just for secondary school entry but also other exams in later schooling. 


\section{References}

Akos, P. (2002). Student perceptions of the transition from elementary to middle school. Professional School Counseling, 5, 339-345.

Aronson, J., Fried, C. B., \& Good, C. (2001). Reducing the effects of stereotype threat on college students by shaping theories of intelligence. Journal of Experimental Social Psychology, 38, 113-125.

Atkinson, A., Gregg, P. and McConnell, B. (2006). The Result of 11Plus Selection: An Investigation into Equity and Efficiency of Outcomes for Pupils in Selective LEAs. CMPO DP no. 06/150.

Barber, B. \& Olsen, J. (2004). Assessing the transitions to middle and high school. Journal of Adolescent Research, 19, 4-23.

Baumeister, R. F. (1993). Self-esteem: The puzzle of low self-regard. New York: Plenum.

Black, S. \& Machin, S. (2010). Housing Valuations of School Performance. In E. Hanushek, S. Machin and L. Woessmann (Eds.) Handbook of the Economics of Education, Amsterdam: Elsevier.

Blackwell, L. S., Trzesniewski, K. H., \& Dweck, C. S. (2007). Implicit theories of intelligence predict achievement across an adolescent transition: a longitudinal study and an intervention. Child Development, 78, 246-63.

Branden, N. (1969). The Psychology of Self-Esteem: A New Concept of Man's Nature. Los Angeles: Nash Publishing.

Brown, J., \& Armstrong, R. (1982). The structure of pupils' worries during transition from junior to secondary school. British Educational Research Journal, 8, 123-131.

Bunting, B. P. \& Mooney, E. (2001). The effects of practice and coaching on test results for educational selection at eleven years of age. Educational Psychology, 21, 243-253. 
Burgess, S., Dickson, M. \& Macmillan, L. (2014). Selective schooling systems increase inequality. Department of Quantitative Social Science. Working Paper 14-09.

Cotterell, J. L. (1986). Adjustment to secondary school. In M. B. Youngman (Ed.), Midschooling transfer: Problems and proposals (pp. 66-86). London: Nelson-NFER.

Crocker, J., Karpinski, A., Quinn, D. M., \& Chase, S. (2003). When grades determine selfworth: Consequences of contingent self-worth for male and female engineering and psychology majors. Journal of Personality and Social Psychology, 85, 507-516.

Crocker, J., \& Wolfe, C. T. (2001). Contingencies of self-worth. Psychological Review, 108, 593-623.

Cunningham, J. D., Gerard, H. B., Miller, N. (1978). Effects of success and ailure on children's perceptions of internal-external locus of control. Social Behaviour and Personality: An International Journal, 6, 1-9.

Douglas, J. (1964) The Home and the School London: MacGibbon and Kee.

Dweck, C.S. (1999). Self-theories: Their role in motivation, personality and development. Philadelphia: Psychology Press.

Dweck, C. S., Chiu, C., \& Hong, Y. (1995). Implicit theories and their role in judgments and reactions: A world from two perspectives. Psychological Inquiry, 6, 267-285.

Eccles, J. S., \& Midgley, C. (1989). Stage- environment fit: Developmentally appropriate classrooms for young adolescents. In C. Ames \& R. Ames (Eds.), Research on motivation in education: Vol. 3. Goals and cognitions (pp. 13-44). New York: Academic Press.

Egan, M. \& Bunting, B. (1991). The effects of coaching on 11+ scores. British Journal of Educational Psychology, 61, 85-91.

Elwood, J. \& Murphy, P. (2002). Tests, tiers and achievement: gender and performance at 16 and 14 in England. European Journal of Education, 37, 395-416 
Evangelou, M., Taggart, B., Sylva, K., Melhuish, E., Sammons, P. \& Siraj-Blatchford, I. (2008), Effective Pre-school, Primary and Secondary Education 3-14 Project (EPPSE 3-14): What Makes a Successful Transition from Primary to Secondary School? Research Report No. DCSF-RR019. Nottingham: DfES Publications

Farkas, G., Grobe, R. Sheehan, D. \& Shaun, Y. (1990). Cultural Resources and School Success: Gender, Ethnicity, and Poverty Groups within an Urban District. American Sociological Review 55, 127-142.

Freudenthaler, H. H., Spinath, B., \& Neubauer, A. C. (2008). Predicting school achievement in boys and girls. European Journal of Personality, 22, 231-245.

Galton, M. Gray, J. \& Ruddock, J. (1999). The Impact of School Transitions and Transfers on Pupil Progress and Attainment. Research Report RR 131 (London, DfEE).

Galton, M., Morrison, I., \& Pell, T. (2000). Transfer and transition in English schools: Reviewing the evidence. International Journal of Educational Research, 33, 341-363.

Gatz, M. \& Karel, M. J. (1993). Individual change in perceived control over 20 years. International Journal of Behavioral Development 16, 305-322.

Grammar School Statistics (2015). Paul Bolton. Briefing paper number 1398. Retrieved November 2015 from: http://www.parliament.uk/briefing-papers/SN01398.pdf

Gibbons, S. \& Machin, S. (2008). Valuing School Quality, Better Transport and Lower Crime. Oxford Review of Economic Policy, 24, 99-119.

Gillborn, D. \& Youdell, D. (2000). Rationing education: Policy, practice, reform and equality. Buckingham: Open University Press.

Gilligan, R. (2000). Adversity, resilience and young people: The protective value of positive school and spare time experiences. Children and Society, 14, 37-47. 
Gutman, L. M., \& Midgley, C. (2000). The role of protective factors in supporting the academic achievement of poor African American students during the middle school transition. Journal of Youth and Adolescence, 29, 223-248.

Heyman, G.D., Dweck, C.S. (1998). Children's thinking about traits: Implications for judgments of the self and others. Child Development, 64(2). 391-403.

Hong, Y., Chiu, C., Dweck, C. S., Lin, D. M. S., \& Wan, W. (1999). Implicit theories, attributions, and coping: A meaning system approach. Journal of Personality and Social Psychology, 77, 588-599.

Jackson, B. and Marsden, D. (1962) Education and the Working Class. London: Routledge and Kegan Paul.

Jennings, K. \& Hargreaves, D. J. (1981). Children's Attitudes to Secondary School Transfer. Educational Studies,__, 35-39.

Kent County Council, 2010

Lefcourt, H. (1976). Locus of control: Current trends in theory and research. New York: Wiley.

Marks, L. I. (1998). Deconstructing locus of control: Implications for practitioners. Journal of Counselling and Development, 76, 251-259.

McFarland, C., \& Ross, M. (1982). Impact of causal attributions on affective reactions to success and failure. Journal of Personality and Social Psychology, 43, 937-946.

McGee, C., Ward, R., Gibbons, J., \& Harlow, A. (2003). Transition to secondary school: a literature review. A Report to the Ministry of Education. Hamilton: University of Waikato: New Zealand.

Mitman, A., \& Packer, M. (1982). Concerns of seventh-graders about their transition to junior high school. Journal of Early Adolescence, 2, 319-338. 
Mikulincer, M. (1994). Human learned helplessness: A coping perspective. New York: Plenum Press.

Murdoch, A. (1986). Forty-two children and the transfer to secondary education. In M. Youngman (Ed.) Mid-schooling Transfer : Problems and Proposals, Windsor, ERNelson.

National Grammar Schools Association (2015). Retrieved 10.11.2015 from: http://www.ngsa.org.uk/index.php

Newman, B. M., Myers, M. C., Newman, P. R., Lohman, B. J., \& Smith, V. L. (2000). The Transition to High School for Academically Promising, Urban, Low-Income African American Youth. Adolescence, 35, 45-66.

Newman, B. M., Newman, P.R., Griffen, S., O’Connor, K., \& Spas, J. (2007). The relationship of social support to depressive symptoms during the transition to high school. Adolescence, 42, 441-459.

Newman, T. \& Blackburn, S. (2002b), Transitions in the Lives of Children and Young People; Resilience Factors (Full Report), Scottish Executive Education Department, accessed November 2014 at http://www.scotland.gov.uk/Resource/Doc/4 6997/0024004.pdf.

Noden, P., West, A., David, M. \& Edge, A (1998) Choices and destinations at transfer to secondary schools in London. Journal of Education Policy, 13, 221-236.

Nowicki, S. \& Strickland, B. (1973). A locus of control scale for children. Journal of Consulting and Clinical Psychology, 42, 148-155.

OCR (2015). Reforming GCSEs: the changing landscape. A summary of what's planned for GCSEs from 2015. Retrieved November 2015 from: http://www.ocr.org.uk/Images/141803-guide-to-the-gcse-changes.pdf 
Oswald, L., Walker, G., Krajewski, K., \& Reilly, E. (1994). General and specific locus of control in cocaine abusers. Journal of Substance Abuse, 6, 179-190.

Otis, N., Grouzet, F., Pelletier, L.G. (2005). Latent Motivational Change in an Academic Setting: A 3-Year Longitudinal Study. Journal of Educational Psychology, 97, 170183.

Reimanis, G. (1974). Effects of Locus of Reinforcement Control Modification Procedures in early Grades and College Students. Journal of Educational Research, 68, 124-127.

Reyes, O., Gillock, K., Kobus, K. \& Sanchez, B. (2000). A Longitudinal Examination of the Transition into Senior High School for Adolescents from Urban, Low-Income Status, and Predominantly Minority Backgrounds. American Journal of Community Psychology, 24, 519-544.

Piers Harris Children's Self-Concept Scale, Second Edition (Piers-Harris 2) (2002).

Rosenthal, R, \& Jacobsen, L. (1968). Pygmalion in the classroom: teacher expectation and pupils' intellectual development. New York: Holt, Rinehart and Winston.

Rotter, J. B. (1990). Internal versus external control of reinforcement: A case history of a variable. American Psychologist, 45, 489-493.

Rotter, J. B. (1975). Some problems and misconceptions related to the construct of internal versus external control of reinforcement. Journal of Consulting and Clinical Psychology, 43, 56-67.

Rotter, J. (1966). Generalized expectancies for internal versus external control of reinforcement. Psychological Monographs 80, 1-28.

Seidman, E., Allen, L., Aber, J. L., Mitchell, C. \& Feinman, J. (1994). The impact of school transitions in early adolescence on the self-system and social context of poor urban youth. Child Development, 65, 507-522. 
Seligman, M. E. P. (1975). Helplessness: On depression, development, and death. San Francisco: Freeman.

Skinner, E. A., Wellborn, J. G., \& Connell, J. P. (1990). What it takes to do well in school and whether I've got it: A process model of perceived control and children's engagement and achievement in school. Journal of Educational Psychology, 82, 22-32.

Shephard, S., Owen, D., Fitch, T. J. \& Marshall, J. L. (2006). Locus of control and academic achievement in high school students. Psychologists Representative. 98, 318-322

Sirsch, U. (2003). The impending transition from primary to secondary school: Challenge or threat? International Journal of Behavioral Development, 27, 385-395.

Stobart, G., White, J., Elwood, J., Hayden, M. \& Mason, K. (1992) Differential performance in examinations at 16+: English and mathematics. London: SEAC.

Smyth, E., McCoy, S., \& Darmody, M., (2004). Moving up: the experiences of first year students in post-primary education. Dublin: Liffey Press.

Thompson, T., Davidson, J. A., \& Barber, J. G. (1995). Self-worth protection to achievement motivation: Performance effects and attributional behaviour. Journal of Educational Psychology, 87, 598-610.

Tobbell, J. (2003). Students experiences of transition from primary to secondary school. Educational and Child Psychology, 20, 4-14.

Vernon, P. E. (1957). Secondary School Selection. London: Methuen.

Wassell, C., Preston, P., \& Jones, H. (2007). Transition: A universal issue. Pastoral Care in Education, 25, 49-53.

West, P., Sweeting, H., Young, R. (2010). Transition matters: pupils' experiences of the primary-secondary school transition in the West of Scotland and consequences for wellbeing and attainment. Research Papers in Education, 25, 21-50. 
Wigfield, A., \& Eccles, J. S. (1994). Children's Competence Beliefs, Achievement Values, and General Self-Esteem: Change Across Elementary and Middle School. Journal of Early Adolescence, 14, 107-138.

Wigfield, A., Eccles, J. S., MacIver, D., Reuman, D. A., \& Midgley, C. (1991). Transitions during early adolescence: Changes in children's domain-specific self-perceptions and general self-esteem across the transition to junior high school. Development Psychology, $27,552-565$. 


\section{Table 1}

Comparison of children within the entrance exam condition who intend to take the exam and those who do not intend to take the exam.

\begin{tabular}{|c|c|c|c|c|}
\hline & \multicolumn{2}{|c|}{$\begin{array}{l}\text { Intend to take } \\
\text { the exam }\end{array}$} & $\begin{array}{l}\text { Do not } \\
\text { take th } \\
(\mathrm{N}=38\end{array}$ & $\begin{array}{l}\text { ntend to } \\
\text { exam }\end{array}$ \\
\hline & M & SD & $\mathrm{M}$ & SD \\
\hline Locus of control $*$ & 30.40 & 3.01 & 28.68 & 3.20 \\
\hline Self-esteem * & 50.53 & 3.97 & 47.29 & 5.99 \\
\hline School system * & 15.68 & 1.88 & 13.81 & 4.67 \\
\hline $\begin{array}{l}\text { Entity theory of } \\
\text { intelligence* }\end{array}$ & 3.88 & 1.31 & 3.26 & 1.19 \\
\hline $\begin{array}{l}\text { Incremental theory } \\
\text { of intelligence* }\end{array}$ & 2.28 & 1.15 & 3.06 & 1.58 \\
\hline
\end{tabular}


Table 2

Comparison of children who passed, failed and did not take the exam.

\begin{tabular}{|c|c|c|c|c|c|c|}
\hline & \multicolumn{2}{|c|}{ Pass $(\mathrm{N}=19)$} & \multicolumn{2}{|c|}{ Fail $(\mathrm{N}=41)$} & \multicolumn{2}{|c|}{ Did not sit $(\mathrm{N}=38)$} \\
\hline & M & SD & M & SD & M & SD \\
\hline Locus of control $*_{\sim}$ & 32.78 & 3.06 & 30.13 & 3.69 & 30.19 & 3.89 \\
\hline Self-esteem $*_{\sim}$ & 47.78 & 2.44 & 43.41 & 5.51 & 44.84 & 4.37 \\
\hline School system & 15.47 & 2.76 & 14.02 & 4.00 & 14.50 & 3.82 \\
\hline Entity theory of intelligence & 4.10 & 1.01 & 4.11 & 1.01 & 3.22 & 1.24 \\
\hline Incremental theory of intelligence $*_{\sim}$ & 2.05 & .90 & 3.44 & 1.32 & 2.87 & 1.18 \\
\hline
\end{tabular}

* Indicates that differences between children who passed and who failed were significant

$\sim$ Indicates that differences between children who passed and those who did not sit the exam were significant. 